International Journal of Computer Networks \& Communications (IJCNC) Vol.4, No.3, May 2012

\title{
MULTI-LAYERED RING LOG-PERIODIC ANTENNAS ARRAY DESIGN FOR GPS SYSTEMS
}

\author{
M. Abri ${ }^{1}$, S. M. Bahloul ${ }^{1}$ and H. Abri Badaoui ${ }^{2}$ \\ ${ }^{1}$ Laboratoire de Télécommunications, Département de Génie Electrique \\ Faculté de Technologie, Université Abou-Bekr Belkaïd -Tlemcen \\ BP 230, Pôle Chetouane, 13000 Tlemcen- Algérie \\ abrim2002@yahoo.fr, salimttl@yahoo.fr \\ ${ }^{2}$ Laboratoire STIC, Département de Génie Electrique \\ Faculté de Technologie, Université Abou-Bekr Belkaïd -Tlemcen \\ BP 230, Pôle Chetouane, 13000 Tlemcen- Algérie \\ elnbh@yahoo.fr
}

\begin{abstract}
The objective of the present study is the design of log periodic ring printed antennas array witch generates circular polarization with wide band by single feed linearly polarized elements for GPS systems. The radiating elements have been fed by magnetic coupling through a slot. The circular polarization is achieved by having a basic $2 \times 2$ sub-arrays with unique element angular and phase arrangement, both the element angular orientation and feed phase are arranged in the $0^{\circ}, 90^{\circ}, 180$ and $270^{\circ}$ fashion. The purpose of different angular orientations of the patches is to generate two orthogonally polarized fields, while -3dB coupler is used to provide the required amplitude and phase delays for circular polarization generation. This uniquely formed array has the capability of generating excellent circular polarization. An association of the coupler with the antennas has been established. This work is completed using the moment's method of Momentum software. Good performances of adaptation and polarization were obtained. The simulation results are then presented and discussed.
\end{abstract}

\section{KEY WORDS}

Ring printed antenna, Right hand circular polarization RHCP, coupler, radiation pattern.

\section{INTRODUCTION}

The telecommunications sector knew an unprecedented growth and diverse services (mobile phone, multimedia services ... etc) are being offered by many systems (cellular system, multimedia, wireless data transfer, satellite systems...etc.). While seeking to optimize the radio electric performances of an antenna, we must adapt it to the most recent applications (space communications, mobile communications and wireless communications or antennas for cars) and fulfil the integration requirements for terminals architecture. The antenna must improve the total radio terminal performances. It is thus necessary to design well adapted antennas, with a high gain, a good purity of polarization, linear or circular functioning on broad frequencies bands often for the planar, omni directional antennas or on the contrary very directing, 
frequency piloting or polarization ...etc. But we also must seek smallest and low cost antennas (we have little place on a mobile terminal) we must have the possibility to integrate components easily in order to ensure other electronic functions. Moreover, the antennas characteristics must remain not very influenceable by the environment.

Frequently, circular polarization is used. Circular polarization is most often use on satellite communications. This is particularly desired since the polarization of a linear polarized radio wave may be rotated as the signal passes through any anomalies (such as Faraday rotation) in the ionosphere. Furthermore, due to the position of the Earth with respect to the satellite, geometric differences may vary especially if the satellite appears to move with respect to the fixed Earth bound station. Circular polarization will keep the signal constant regardless of these anomalies. In addition, antennas with circular polarization radiation have found wide applications in mobile satellite communications and direct satellite broadcasting systems due to their insensivity to the ionospheric polarization rotation. Many types of microstrip antennas have been proposed and investigated [1-3].

Many antennas use a wide frequency range, from this log-periodic antennas. They are multiple element antennas whose length and the gap between the components is increasing steadily in geometrical progression.

From what has been discussed, this work focuses on the study of a multilayered ring printed antennas array in log periodic arrangement.

\section{DeSign Procedure}

For the development of this array, two procedures were used. The first is to develop the feed circuit (Figure 1) and the second to associate it with the ring antenna in log-periodic architecture.

\subsection{Feed circuit}

The reason that a circularized array can be constructed by linearly polarized elements is primarily attributed to a four-element sub-array with unique angular and phase arrangements. This basic sub-array has its elements arranged in a $2 \times 2$ square or rectangular grid configuration with element angular orientation and feed phase arranged in either a $0^{\circ}, 90^{\circ}, 180^{\circ}, 270^{\circ}$ fashion. An example that uses microstrip patches is illustrated in Figure 1. The purpose of different angular orientations of the patches is to generate two orthogonally polarized fields, while different feed phases are used to provide the required phase delays for CP generation. It is well known that the circular polarization can be achieved in the broadside direction of an array composed of two linearly polarized elements with angle and phase arranged in $0^{\circ}, 90^{\circ}$ fashion as shown in Figure. 2(a). The CP in this arrangement, however, becomes very poor at angles greater than $5^{\circ}$ off broadside direction in the $\mathrm{x}-\mathrm{z}$ plane. This is caused by the spatial delay $\left(\Delta \Psi^{\circ}=k_{0} \Delta x \sin \theta\right.$, see Figure 2 (b)) formed between the two orthogonally polarized elements. This spatial delay, which disturbs the required $90^{\circ}$ phase, contributes to the poor $\mathrm{CP}$ quality at angles off broadside. 


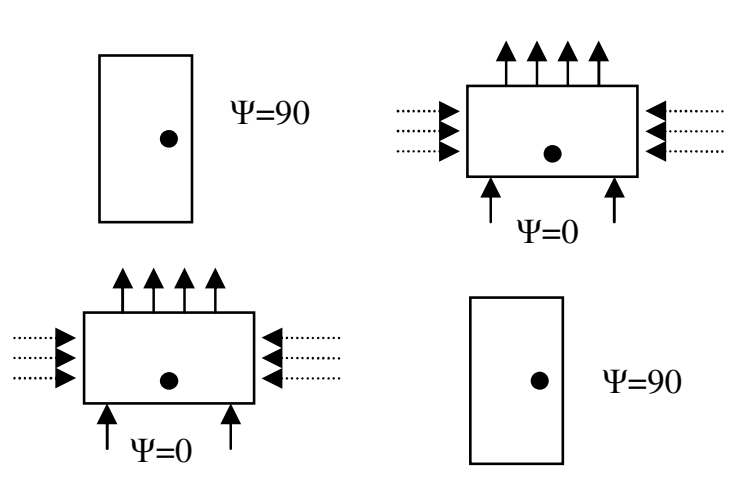

(a)

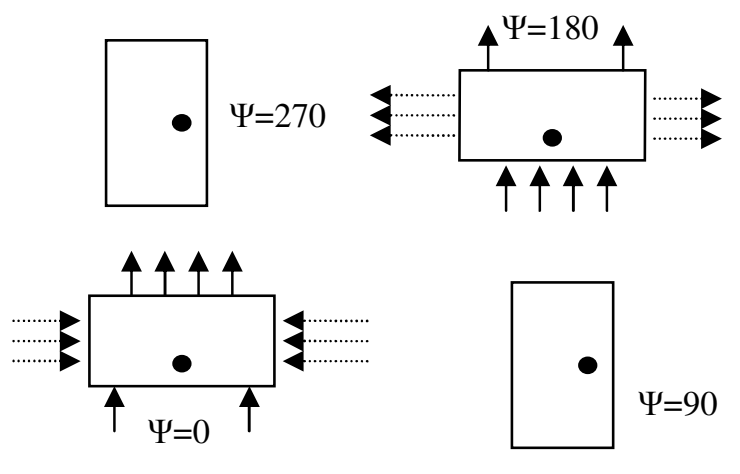

(b)

Figure 1. $2 \times 2$ microstrip arrays that generate CP with LP elements.

(a) $0^{\circ}, 90^{\circ}, 0^{\circ}, 90^{\circ}$ arrangement for narrow-band application,

(b) $0^{\circ}, 90^{\circ}, 180^{\circ}, 270^{\circ}$ arrangement for wide-band application

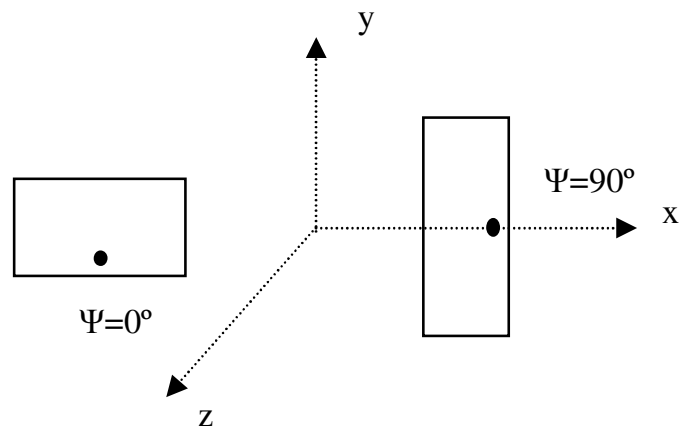

(a)

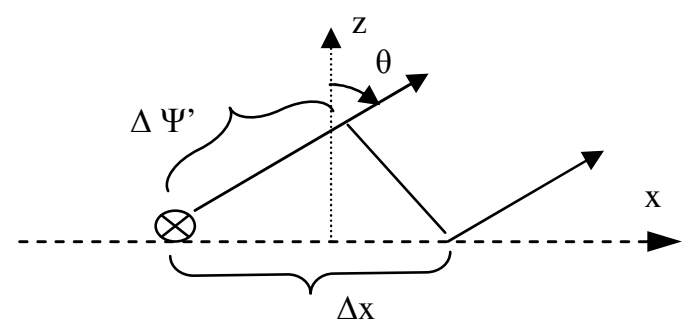

(b)

Figure $2 . \quad$ (a) Two-element microstrip array with $0^{\circ}, 90^{\circ}$ arrangement,

(b) Its spatial phase delay $\Delta \Psi^{\prime}=k_{0} \Delta x \sin \theta$

In our case, the circular polarization is achieved by having a basic $2 \times 2$ sub-arrays with element angular and phase arrangement, both the element orientation and feed phase are arranged in $0^{\circ}$, $90^{\circ}, 180^{\circ}, 270^{\circ}$ fashion. Thus, the feed network of the four elements of array is obtained by using a coupler with four output terminals in order to obtain a circular polarization during simulation, these circuits must present:

- A phase of $90^{\circ}$ between two consecutive terminal port,

- An amplitude level of - $6 \mathrm{~dB}$ compared to the maximum on each terminal port, 
Where:

- Coupler $-3 \mathrm{~dB}, 180^{\circ}$ is selected, in both cases, a Rat-race coupler of 4 terminal ports of a compact ring in order to reduce its maximum size.

- A branch coupler - $3 \mathrm{~dB}, 90^{\circ}$ for dividing the incident signal into two output signals of same amplitude and phase shifted by $90^{\circ}$ with respect to each other. A matched load must be placed on one of the termination ports in order to absorb the reflected signal by each output in order to ensure good insulation.

The mask of the supply circuit for the right hand circular polarization (RHCP) developed is shown in Figure 3.

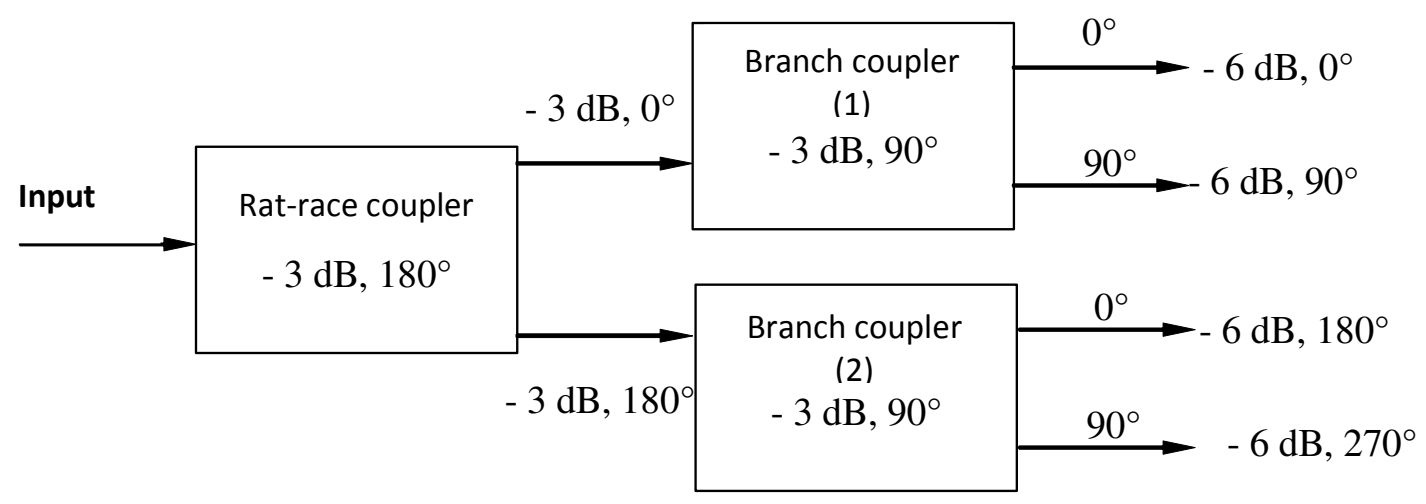

Figure 3. Diagram block of the feed network for RHCP polarization.

The Mask layout of the right hand circular polarization circuit generation is shown in figure 4 .

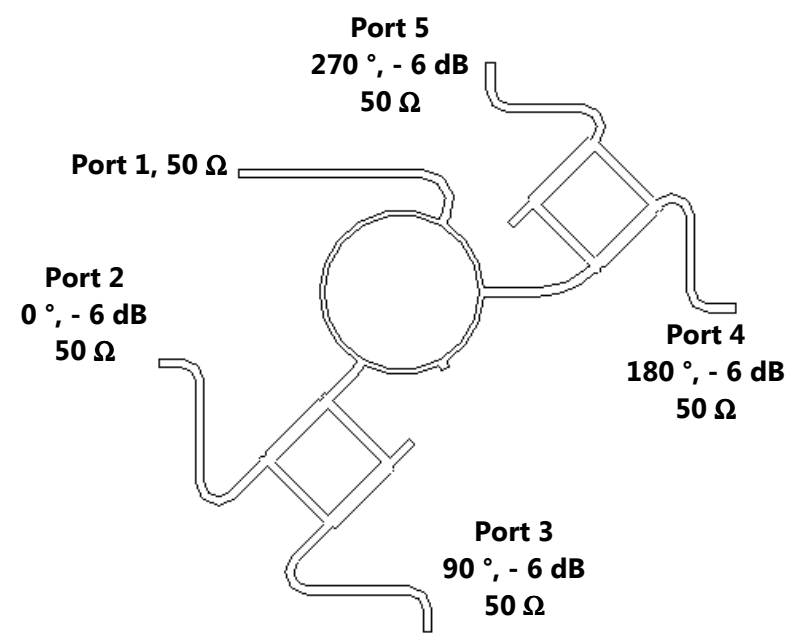

Figure 4. The Mask layout of the circuit for right hand circular polarization generation. 


\subsection{Antenna caracteristics}

We first seek to determine the dimensions of the antenna to obtain the correct resonant frequency. The circuit is designed to be associated with the antennas. A parametric study of the basic element which is a ring antenna is established in order to adapt the frequency $1.227 \mathrm{GHz}$. The radiating element characteristics are [4-5] :

- $\mathrm{r}_{2}=41,5 \mathrm{~mm} ; \mathrm{r}_{1}=27,5 \mathrm{~mm}, \mathrm{~T}=0,035 \mathrm{~mm}$;

- Radiating element substrate : $\varepsilon \mathrm{r}_{1}=2,2, \mathrm{H}_{1}=1.52 \mathrm{~mm}, \operatorname{tg} \delta_{1}=0,002$;

- Slot : $\mathrm{W}_{\mathrm{S}}=0,8 \mathrm{~mm}, \alpha=120^{\circ}$;

- Air layer $\varepsilon \mathrm{r}_{2}=1, \mathrm{H}_{2}=15 \mathrm{~mm}, \operatorname{tg} \delta_{2}=0$;

- Feed substrate : $\varepsilon \mathrm{r}_{3}=2,2 ; \mathrm{H}_{3}=0,762 \mathrm{~mm} ; \operatorname{tg} \delta_{3}=0,002$;

- Microstrip line : 4,74 mm;

- Stub: $\mathrm{Ls}=8,07 \mathrm{~mm}$.

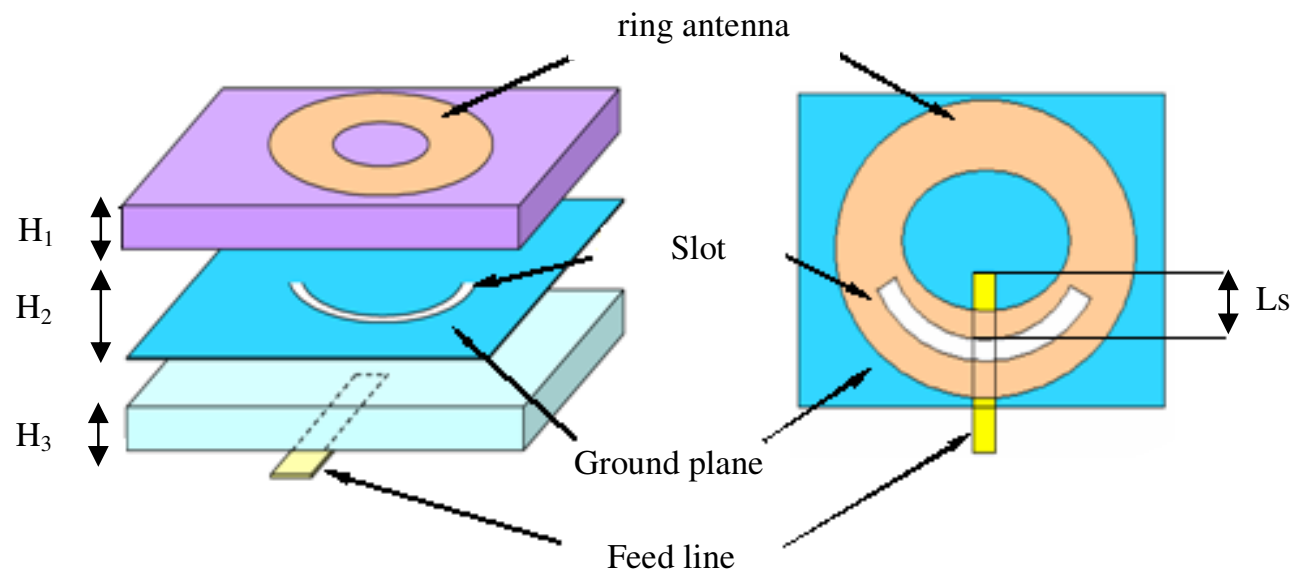

Figure 5. Geometry of the sloted antenna supplied by sector.

\section{Log periodic concept}

The log-periodic antennas are antennas elements which increase steadily in geometric progression [6-9].

If $r_{\mathrm{n}}$ represents a dimension of $n^{\text {th }}$ cell and $r_{\mathrm{n}+1}$ is the $(\mathrm{n}+1)^{\text {th }}$ cell is found then the relationship: 
$\tau=\frac{\mathrm{r}_{\mathrm{n}+1}}{\mathrm{r}_{\mathrm{n}}}$

Consequently, the arrays have the same properties of radiation at all frequencies which are connected by the periodicity factor $\tau$.

$\mathrm{f}_{1}, \mathrm{f}_{2}=\tau . \mathrm{f}_{1}, \mathrm{f}_{3}=\tau^{2} \mathrm{f}_{1}, \mathrm{f}_{4}=\tau^{3} \mathrm{f}_{1}$

With:

It is noted that:

$\ln \frac{f_{2}}{f_{1}}=\ln \tau ; \ln \frac{f_{3}}{f_{1}}=2 \ln \tau$

\section{Simulation results}

For circular polarization in the bands of GPS operation $\mathrm{L}_{1}$ and $\mathrm{L}_{2}$, we determined by the $\log$ periodic concept as shown in Table 1 four antennas covering the frequency range from $1.1 \mathrm{GHz}$ to $1.575 \mathrm{GHz}$ in order to associate it with the feed circuit system, the periodicity factor is chosen such is : $\tau=1,127$.

TABLEAU I. Frequency and size of the radiating elements

\begin{tabular}{|c|c|c|c|c|c|}
\hline Elements & Frequency [GHz] & $\begin{array}{c}\mathbf{r}_{\mathbf{2}} \\
{[\mathbf{m m}]}\end{array}$ & $\begin{array}{c}\mathbf{r}_{\mathbf{1}} \\
{[\mathbf{m m}]}\end{array}$ & $\begin{array}{c}\mathbf{L}_{\mathbf{s}} \\
{[\mathbf{m m}]}\end{array}$ & $\begin{array}{c}\mathbf{W}_{\mathbf{L}} \\
{[\mathbf{m m}]}\end{array}$ \\
\hline 1 & 1,10 & 55,25 & 13,75 & 34,7 & 4,7 \\
2 & 1,23 & 41,75 & 27,25 & 15,1 & 4,7 \\
3 & 1,39 & 34 & 18 & 14,70 & 4,7 \\
4 & 1,57 & 26 & 18 & 8,10 & 4,7 \\
\hline
\end{tabular}

The reflected power at the input of each antenna are shown in figure 6 : 
International Journal of Computer Networks \& Communications (IJCNC) Vol.4, No.3, May 2012

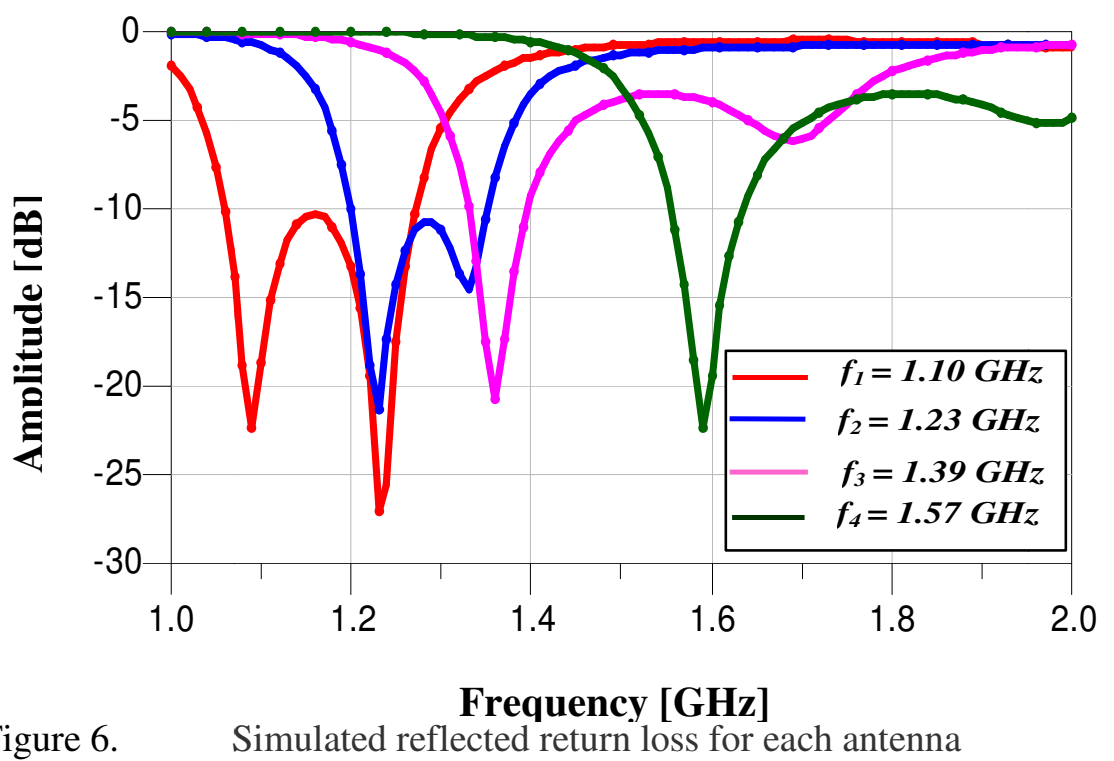

The reflection coefficient shown in Figure 6 reflects the different antennas used and the good adaptation obtained at the resonant frequency of each antenna since the levels of the peaks are less than $-20 \mathrm{~dB}$.

In what follows, we will combine the four antennas, each adapted in its resonant frequency with the adapted coupler to the operating frequency band $[1.1 \mathrm{GHz}-1.575]$ intended to have the right circular polarization (RHCP: Right hand circular polarization).

The mask of the log-periodic ring antennas array associated with the Rat-race coupler is shown in figure 7.

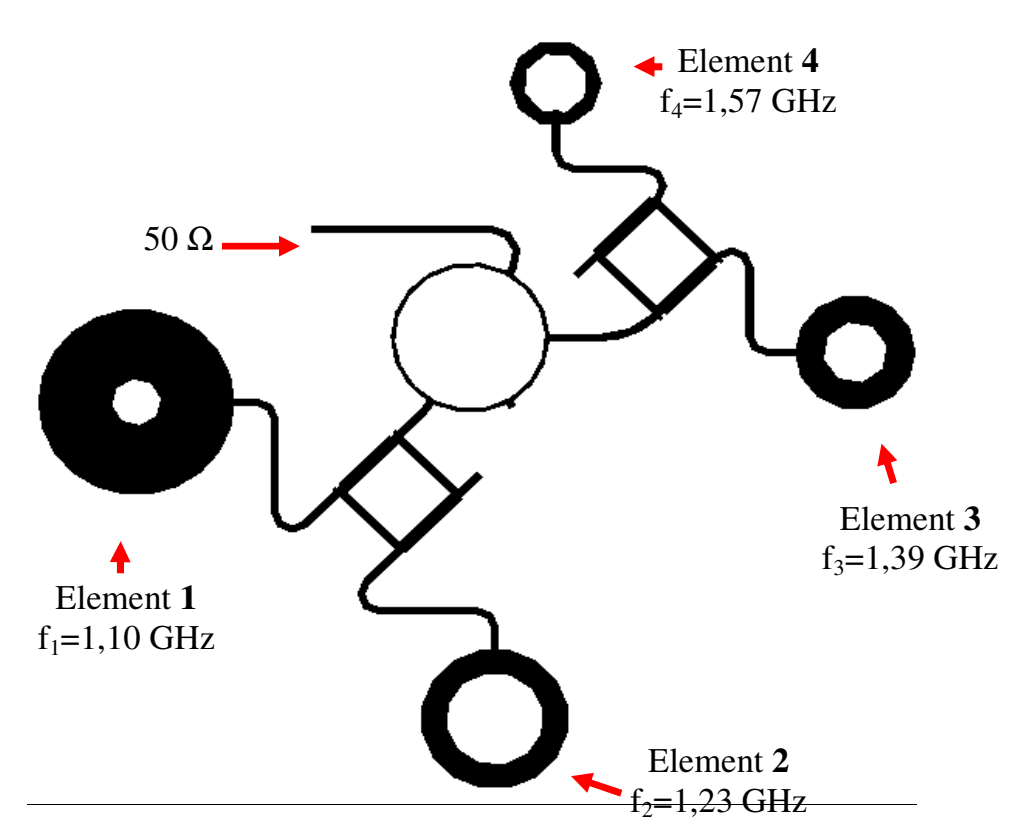

Figure 7. The mask layout of the RHCP ring log-periodic antennas array 
The reflected return loss of the right circular polarization antennas array is shown in Figure 8 in the band [1-1.8 GHz]. Notice from this figure, that the peak corresponds to the resonance frequency in the band L2 is of about $-19.46 \mathrm{~dB}$ with a band of $4.87 \%$, and that which corresponds to the resonance frequency in the L1 band is of about $-29.40 \mathrm{~dB}$ with a band of $8.11 \%$. This confirms the good results obtained in terms of adaptation at the two band of GPS system operation.

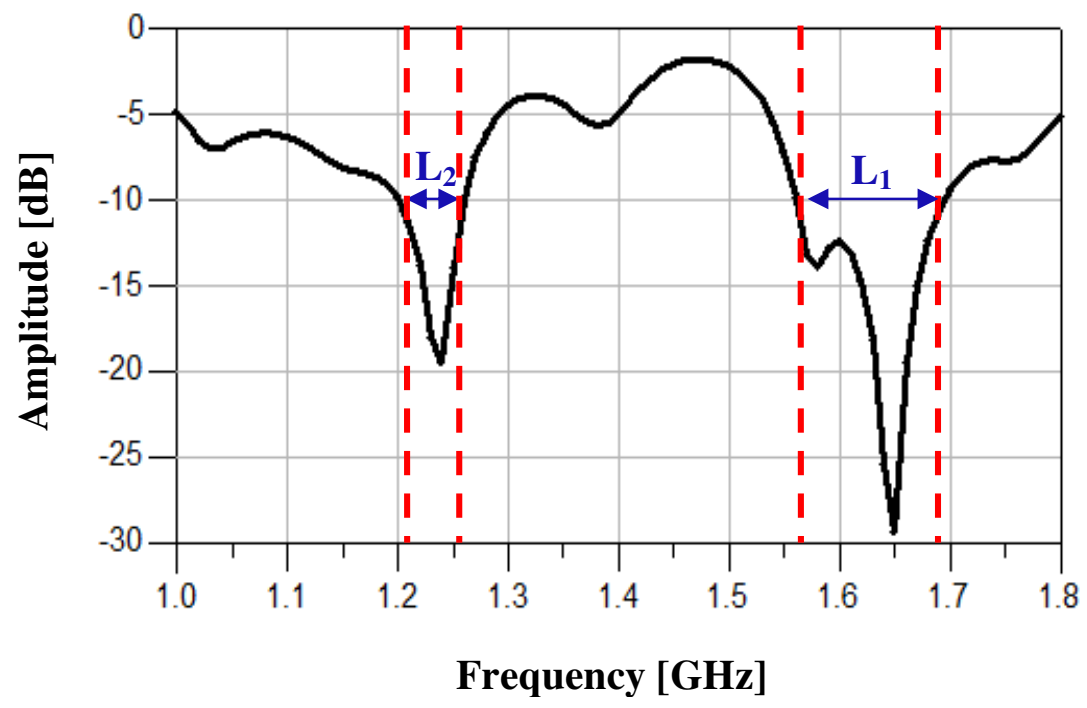

Figure 8. Antennas array computed imput return

We present respectively in figure 9 and 10 the radiation patterns in three dimensions at the frequency $1.227 \mathrm{GHz}(\mathrm{L} 2)$ and at the frequency $1.575 \mathrm{GHz}(\mathrm{L} 1)$.

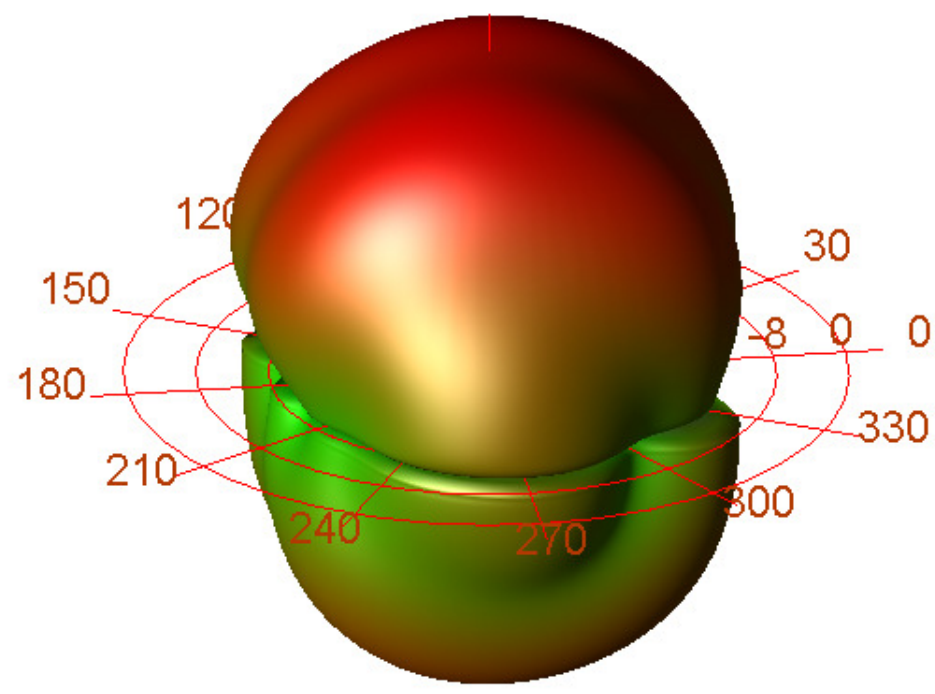

Figure 9. Radiation pattern in 3D of the antennas array ( $f=1,227 \mathrm{GHz})$. 


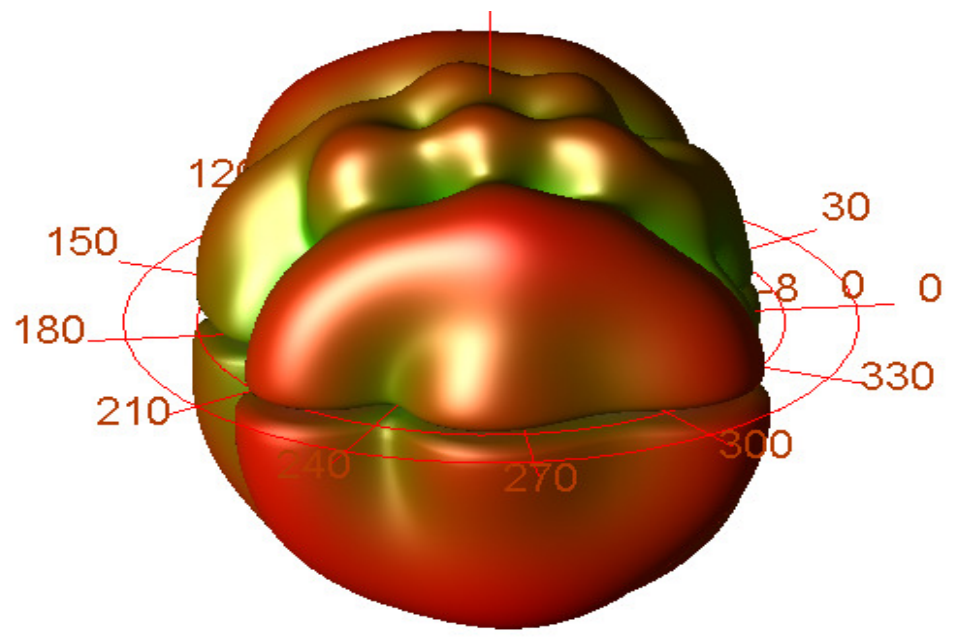

Figure 10. Radiation pattern in 3D of the antennas array ( $f=1,575 \mathrm{GHz})$.

In Figure 9, we note that the radiation patterns in both $\mathrm{E}$ and $\mathrm{H}$ planes are characterized by a fairly good symmetry with respect to the direction $\theta=0{ }^{\circ}$ with the maximum power points towards this direction. The computed gain is $5.75 \mathrm{~dB}$.

Notice from figure 10 and for the the first view, we note that the radiation patterns show an asymmetry with respect to the direction $\theta=0^{\circ}$, the radiation pattern is characterized by a wavy lobes whose amplitude is between -5 and $-10 \mathrm{~dB}$ with the appearance of two lobes directed along the direction $\theta=-35^{\circ}$ and $\theta=40^{\circ}$. The gain corresponding to this band is of about $4.62 \mathrm{~dB}$.

The axial ratio of the RHCP log periodic ring antennas array in the $\mathrm{E}$ plane and $\mathrm{H}$ plane corresponds to this frequency is shown in figure 11.

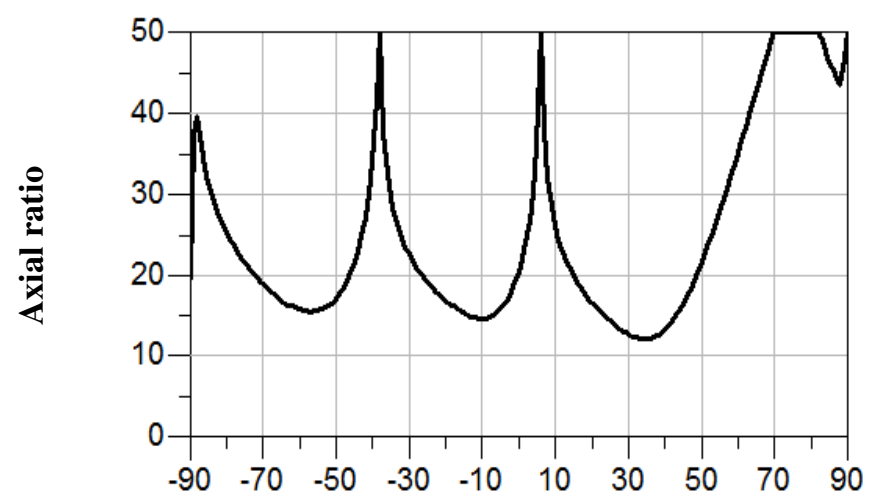

Theta $\left[{ }^{\circ}\right]$

(a) 
International Journal of Computer Networks \& Communications (IJCNC) Vol.4, No.3, May 2012

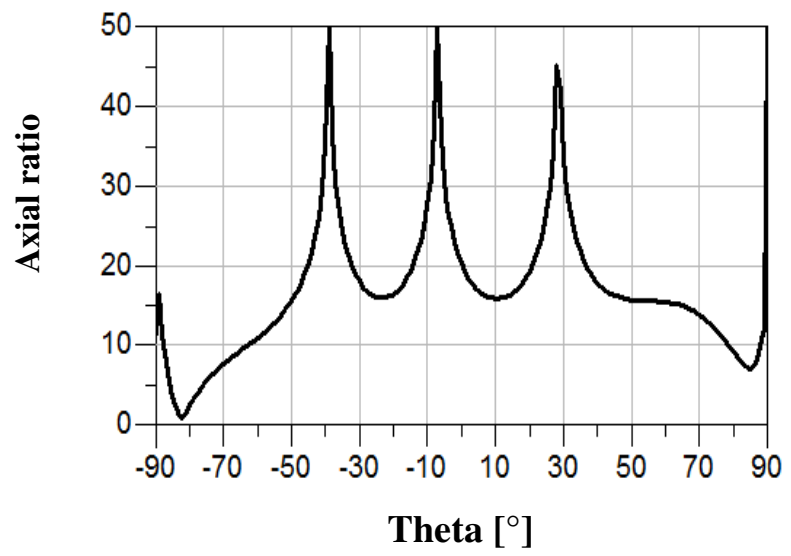

(b)

Figure 11. Axial ratio ( $\mathrm{f}=1,227 \mathrm{GHz}$ ). (a) E Plane ; (b) H Plane

As shown in figure 11, a good right hand circular polarization is obtained in the directions where the amplitude is less than 10 in the $\mathrm{E}$ and $\mathrm{H}$ plane.

The Figure 12 shows that good right circular polarization is achieved for both planes, since the magnitude of the axial ratio in the E plane is lower than 10 in all directions except [-90 $\left.{ }^{\circ},-70\right]$, [$\left.60^{\circ},-50^{\circ}\right],\left[-15^{\circ},-10^{\circ}\right],\left[5^{\circ}, 10^{\circ}\right]$ and $\left[30^{\circ}, 90^{\circ}\right]$.

For the $\mathrm{H}$ plane, one obtains a good polarization in the ranges $\left[-5^{\circ}, 20^{\circ}\right]$ and $\left[20^{\circ}, 30^{\circ}\right]$. This implies that the field in the right hand circular polarization dominates in these directions.

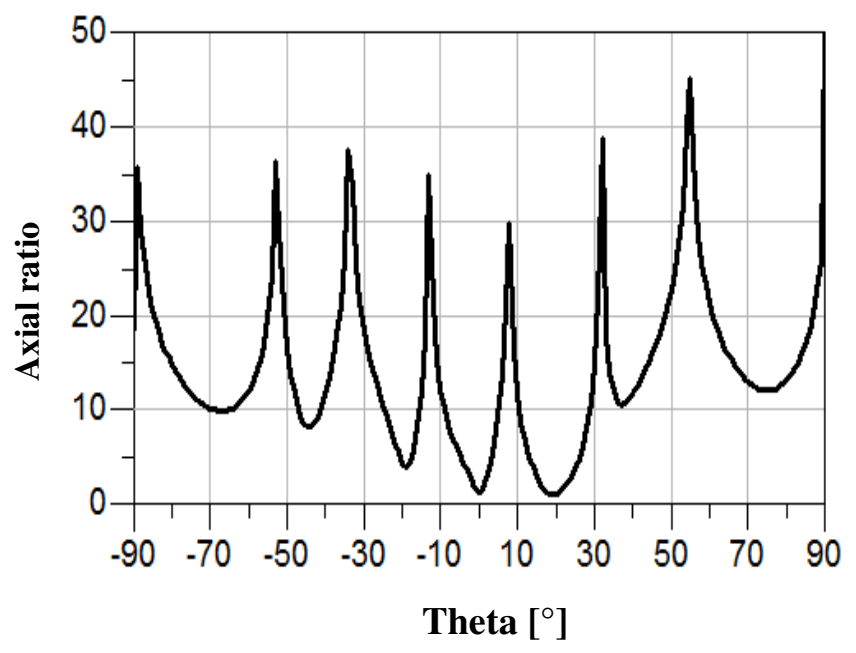

(a) 


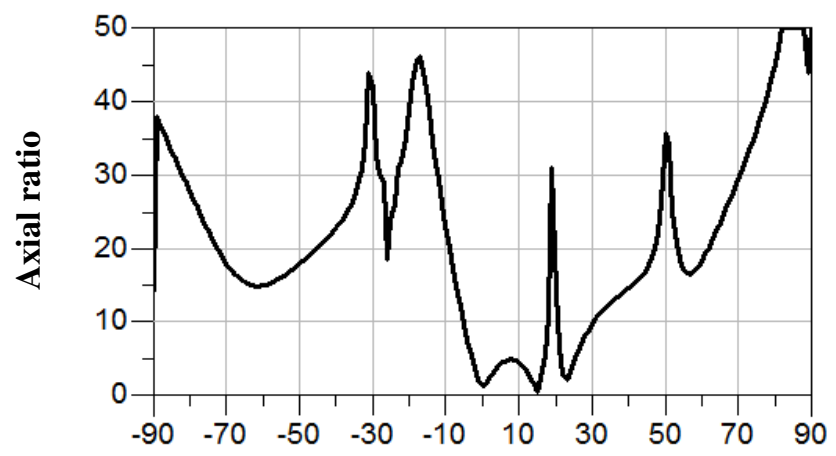

Theta $\left[{ }^{\circ}\right]$

(b)

Figure 12. Axial ratio $(\mathrm{f}=1,575 \mathrm{GHz})$

(a) E Plane; (b) H Plane

\section{Conclusion}

In this paper, a right hand circularly polarized log periodic ring microstrip patch antennas array operating at two bands of the GPS system have successfully been built.

The log-periodic arrangement proposed of printed antennas has allowed to obtain a dual band behavior. Two bands corresponding to the frequency $\mathrm{L}_{1}$ and $\mathrm{L}_{2}$ of GPS system applications with high bandwidth and acceptable gain are achieved. Also a good polarization purity was obtained.

We showed the possibility of tending towards an optimal integration of a radiating element associated its feed circuit. The results presented are encouraging and show that in spite complexity, Circular polarization based on under network with four elements proves more satisfactory.

\section{References}

[1] M. Abri, N. Boukli-hacene et F. T. Bendimerad, «Application du Recuit Simulé à la Synthèse des Réseaux d'Antennes Imprimées en forme d'anneaux » Annales des télécommunications, 60, $\mathrm{N}^{\circ} 11$ 12, pp. 1424-1440, 2005.

[2] M. Abri, N. Boukli-hacene, F. T. Bendimerad and E. Cambiaggio, " Design of a Dual Band Ring Printed Antennas Array”, Microwave journal, vol. 49, no. 5, pp. 228-232, May. 2006.

[3] M. Abri, N. Boukli-hacene and F. T. Bendimerad, "Ring printed antennas arrays radiation. Application to multibeam“., Mediterranean Microwave Symposium, Marseille, France, June 2004.

[4] M. Abri, 'Conception et réalisation de structures d'antennes imprimées multi-bandes ', Thèse de Doctorat, Université Abou Bekr Belkaid Tlemcen, juin 2008. 
International Journal of Computer Networks \& Communications (IJCNC) Vol.4, No.3, May 2012

[5] Abri. M., Boukli-hacene. N and Bendimerad. F. T., 'Application du recuit simulé à la synthèse d'antennes en réseau constituées d'éléments annulaires imprimés' Annales des télécommunications, 60, N¹1-12, pp. 1424-1440, 2005.

[6] Abri. M., Bendimerad. F. T., Boukli-hacene. N and Bousahla. M., 'A Log Periodic Series-Fed Antennas Array Design Using a Simple Transmission Line Model'. International Journal of Electronics and Communication Engineering ISSN 0974-2166 Volume 2, Number 3, pp. 161-169, 2009.

[7] Abri. M., F. T. Bendimerad., N. Boukli-hacene., A. Benzenine et A. Laribi., "Un Simple modèle pour la Synthèse des Réseaux d'Antennes Imprimmés log périodiques “., 4eme Séminaire sur les systèmes de détection architecture et technologie DAT’2008. Alger, 23-25 Novembre 2008.

[8] Romodin. V. B, Oznobikhin. V. I and Kopylov. V. V, 'Log Periodic Microstrip Array', IEEE-Russia conference, MIA-ME '99m 1999.

[9] R. Kakar and G. Kumar, ' Stagger Tuned Microstrip Log Periodic Antenna', IEEE conference, 1996. 